\title{
An Experimental Study on the Mass Transfer Rate of Droplets in Annular Two-Phase Flow*
}

\author{
Tomio OKAWA**, Naoya SHIMADA** ${ }^{* *}$ Akio KOTANI** and Isao KATAOKA**
}

\begin{abstract}
Deposition rate of droplets in annular flow was measured to elucidate the effect of the shape of flow obstacles that were placed in a flow channel. In the present experiments, the test section was a vertical round tube of $5 \mathrm{~mm}$ in inside diameter, air and water were used as test fluids, and double film extraction technique was adopted for the measurement. Seven flow obstacles were tested; three obstacles were tubular in shape while other four obstacles were also cylindrical but the cross-sectional areas were varied smoothly in the axial direction. It was revealed that the deposition rate of droplets markedly increased if the present small flow obstacle was placed in the test section tube. The increasing rate was dependent primarily upon the cross-sectional shape of flow obstacle at the maximum cross-sectional area.
\end{abstract}

Key Words: Multi-Phase Flow, Pipe Flow, Annular Flow, Droplet, Deposition, Experiment, Flow Obstacle, Obstacle Shape

\section{Introduction}

Annular flow is a particularly important flow pattern in gas-liquid two-phase flow since it occurs in a wide range of vapor quality. In this flow pattern, the liquid phase moves partly as a liquid film on the tube wall and partly as droplets in the vapor core. There exists mass transfer between the liquid film and droplets because of the deposition of droplets and the atomization of liquid film. It is known that, to a good approximation, the occurrence of critical heat flux condition in annular regime corresponds to the disappearance of liquid film ${ }^{(1)}$. Since the flowrate of liquid film is increased by the droplet deposition while decreased by the droplet entrainment, accurate evaluations of these two rate processes are of importance in predicting the critical heat flux in annular regime ${ }^{(2)-(4)}$. Thus, extensive measurements of deposition rate and entrainment rate were conducted and also many correlations were developed $^{(5)-(13)}$.

It is known experimentally that the critical heat flux in forced convective flow boiling may be improved if a flow obstacle is placed in a boiling channel ${ }^{(14)-(17)}$. Thus, several empirical correlations for the critical heat flux include the factor to account the effect of flow obstacle ${ }^{(16),(18)}$. On the other hand, several researchers performed particle

* Received 1st September, 2005 (No. 05-4152)

** Department of Mechanical Engineering, Osaka University, 2-1 Yamadaoka, Suita-shi, Osaka 565-0871, Japan. E-mail: t-okawa@mech.eng.osaka-u.ac.jp tracking simulation to deduce the deposition rate numerically ${ }^{(19),(20)}$. It was pointed out in these numerical studies that the deposition rate is strongly influenced by the turbulence structure in high velocity gas core flow. Since the gas core flow should be affected if an obstacle is placed in a flow channel, it is plausible that the deposition rate of droplets is also influenced by the existence of flow obstacle. It is hence inferred that the deposition augmentation by a flow obstacle is one of the primary reasons of the improvement of critical heat flux. This deduction may be supported by several experimental studies that reported the effect of a flow obstacle to increase the film flowrate in annular regime ${ }^{(21),(22)}$.

In nuclear fuel assemblies, rod spacing devices called grid spacer are frequently used to maintain the crosssectional configuration among fuel rods. Since the grid spacer in nuclear reactor core is regarded as the flow obstacle placed in the subchannels, sufficient understanding of the influence of a grid spacer on the deposition rate of droplets is necessary in order to estimate accurately the critical heat flux in nuclear reactor core and to improve the spacer design. However, experimental investigation for the influence of flow obstacle on the deposition rate of droplets is scarce in literature.

In view of these, the authors conducted double film extraction experiments to elucidate the effect of a flow obstacle on the deposition rate of droplets in annular twophase flow $^{(23)}$. It was shown that the deposition rate markedly increases if a small tubular obstacle is placed 
concentrically in the test section round tube. This implies that the film flowrate is significantly underestimated and consequently the critical heat flux in annular regime may also be underestimated if the effect of flow obstacle on droplet behavior is not taken into consideration. It is thus considered that the sufficient understanding on the effect of flow obstacle on the deposition rate of droplets is indispensable for predicting accurately the critical heat flux in annular regime. In this study, the dependence of deposition rate on the obstacle geometry is tested experimentally. In particular, the investigations are focused on the influence of axial variation of cross-sectional shape of tubular obstacles.

\section{Nomenclature}

$C$ : Droplet concentration $\left[\mathrm{kg} / \mathrm{m}^{3}\right]$

$D:$ Tube diameter [m]

$d:$ Obstacle diameter $[\mathrm{m}]$

$G$ : Mass flux $\left[\mathrm{kg} / \mathrm{m}^{2} \mathrm{~s}\right]$

$J:$ Volumetric flux $[\mathrm{m} / \mathrm{s}]$

$K$ : Proportionality factor [dimensionless]

$k:$ Mass transfer coefficient $[\mathrm{m} / \mathrm{s}]$

$m$ : Mass transfer rate $\left[\mathrm{kg} / \mathrm{m}^{2} \mathrm{~s}\right]$

$P$ : Pressure $[\mathrm{Pa}]$

$R e:$ Reynolds number [dimensionless]

$z:$ Axial coordinate $[\mathrm{m}]$

$z_{\mathrm{s}}$ : Distance of obstacle from first extraction unit [m]

Greek symbols

$\beta_{\mathrm{b}}$ : Blockage ratio [dimensionless]

$\beta_{\mathrm{d}}$ : Diameter ratio [dimensionless]

$\rho:$ Density $\left[\mathrm{kg} / \mathrm{m}^{3}\right]$

$\sigma:$ Surface tension $[\mathrm{N} / \mathrm{m}]$

Superscript

$*$ : Dimensionless

Subscripts

$0:$ Average

$1:$ Inlet

$2:$ Outlet

c : Critical

d : Deposition, Droplet, or Downstream

$\mathrm{f}$ : Liquid film

$\mathrm{g}:$ Gas phase

$i$ : Inside

$1:$ Liquid phase

$\mathrm{o}$ : Outside

$\mathrm{s}:$ Obstacle section

$\mathrm{u}:$ Upstream

\section{Experimental Description}

\subsection{Flow loop}

Experiments were carried out with an adiabatic upward air-water flow loop that is shown schematically in Fig. 1 and was described in detail in authors' previous paper $^{(23)}$. The test section consisted of stainless steel tubes

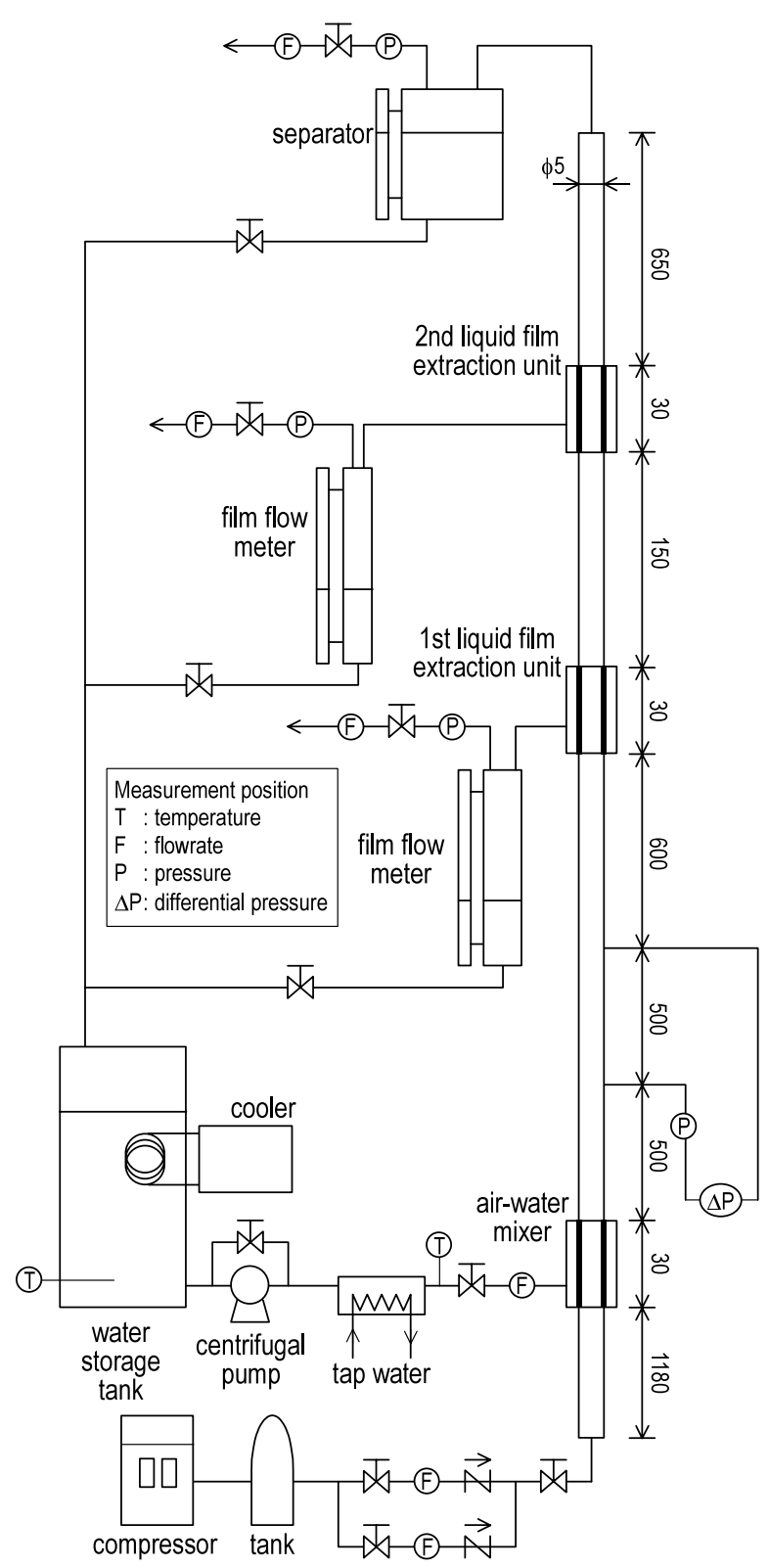

Fig. 1 Schematic of adiabatic air-water flow loop

of $5 \mathrm{~mm}$ in inside diameter. An oil-free compressor was used to supply air from the bottom of test section; two mass flow controllers measured the different ranges of air flowrate. A centrifugal pump derived filtrated and deionized tap water from a storage tank to air-water mixer. A cooler and a heat exchanger were used to keep the water temperature near ambient temperature. The tube wall at the air-water mixing section was made of a porous stainless steel with $0.1 \mathrm{~mm}$ porosity to supply water as a liquid film from the periphery of the test section tube. The length of porous tube was $30 \mathrm{~mm}$ and the inside diameter was the same as that of test section.

Figure 2 illustrates the schematic of the flow configuration expected in the test section tube. The liquid film flow is established at the air-water mixer but a portion 
of liquid is entrained into the gas core flow as the liquid phase goes up the test tube; a portion of the entrained droplets are then deposited on the liquid film. Sufficiently downstream from the mixing section, the deposition rate might be balanced with the entrainment rate. Thus, the flowrates of droplets and liquid film become almost constant and the flow reaches the quasi-equilibrium state. In the present flow loop, the two liquid film extraction units were equipped downstream from the air-water mixer. The distance between the mixer and the first unit was $1.6 \mathrm{~m}$ (320 tube diameters) and the two units were connected with an acrylic tube of $5 \mathrm{~mm}$ in inside diameter. From the correlation by Ishii and Mishima ${ }^{(11)}, 250$ tube diameters is sufficient to ensure fully developed annular flow for all the experimental conditions tested. It is hence considered that the flow reached the quasi-equilibrium state at the first extraction unit. Two porous tubes were used for the first and second liquid film extraction units. At the first film extraction unit, the liquid film was completely extracted by means of the porous wall extraction technique; the detailed description of this technique is found in Ref. (24). The extracted liquid was stored in the film flowrate measuring tank to calculate the flowrate of extracted liquid from the increasing speed of water level in the tank. The increasing speed was measured with a stopwatch. Since the film flowrate was unsteady, some of the gas phase should also be extracted for the complete extraction of liquid film. Two rotameters were used to measure different

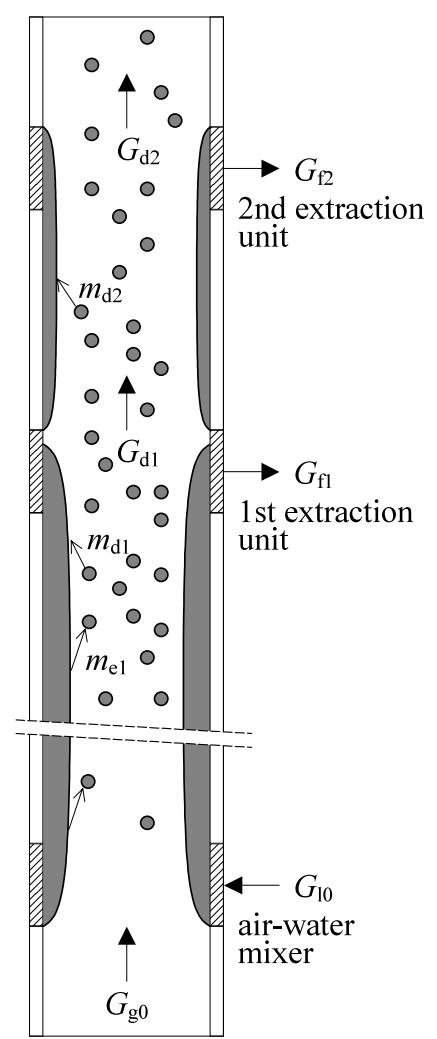

Fig. 2 Flow configuration expected in the test section ranges of the extracted air flowrate. The flowrate of extracted liquid increased with the flowrate of extracted gas when the extracted gas flowrate was not enough, while the extracted liquid flowrate was insensitive to the extracted gas flowrate when adequate amount of air was extracted. This implies that the liquid film was completely extracted but the droplets were not readily diverted into the porous section. In the present experiments, the ratio of extracted air flowrate was varied within $1-20 \%$ of total air flowrate. It was postulated that the extracted liquid flowrate corresponded to the film flowrate in the case that the variation of extracted liquid flowrates was less than $5 \%$ even when the extracted gas flowrate was doubled. This criterion was satisfied in most experimental conditions if the flow pattern in the test section was estimated annular flow from the correlation by Wallis ${ }^{(25)}$.

The water temperature was measured at the exit of heat exchanger with a type-K thermocouple. The system pressure was controlled with the valve that was equipped at the top of separator. The pressure and differential pressure were measured between the mixing section and the first extraction unit. The pressure gradient was assumed constant along the test tube to estimate the pressure at the first film extraction unit. The measurements of temperature, pressure, differential pressure and the flowrates of air and water at the mixing section were recorded every one second with a data acquisition system that was connected with a personal computer.

\subsection{Flow obstacles}

To investigate the influence of flow obstacle on the deposition rate of droplets, a small tubular piece was placed concentrically in the redeposition section between the two film extraction units. The specifications and schematic diagram of seven flow obstacles tested in the present experiments are shown in Table 1 and Fig. 3, respectively. All the obstacles were $20 \mathrm{~mm}$ in length; this was approximately $11 \%$ of $180 \mathrm{~mm}$ long redeposition section. The crosssections of three obstacles X1, X2 and S2 were constant in the axial direction and the cross-sectional areas were within $10-48 \%$ of the cross-sectional area of test section tube of $5 \mathrm{~mm}$ in inside diameter. The cross-sectional ar-

Table 1 Specifications of flow obstacles

\begin{tabular}{cccccc}
\hline Type & $\begin{array}{c}d_{\mathrm{i} 1} \\
(\mathrm{~mm})\end{array}$ & $\begin{array}{c}d_{\mathrm{o} 1} \\
(\mathrm{~mm})\end{array}$ & $\begin{array}{c}d_{\mathrm{i} 2} \\
(\mathrm{~mm})\end{array}$ & $\begin{array}{c}d_{\mathrm{o} 2} \\
(\mathrm{~mm})\end{array}$ & $\begin{array}{c}z_{\mathrm{s}} \\
(\mathrm{mm})\end{array}$ \\
\hline $\mathrm{X} 1$ & 3.6 & 4.0 & 3.6 & 4.0 & 20 \\
$\mathrm{X} 2$ & 2.0 & 4.0 & 2.0 & 4.0 & 20 \\
$\mathrm{~S} 2$ & 1.8 & 2.4 & 1.8 & 2.4 & 20 \\
$\mathrm{~N} 1$ & 2.0 & 4.0 & 3.6 & 4.0 & 54 \\
$\mathrm{~N} 1 \mathrm{R}$ & 3.6 & 4.0 & 2.0 & 4.0 & 54 \\
$\mathrm{~N} 2$ & 2.0 & 2.4 & 2.0 & 4.0 & 54 \\
$\mathrm{~N} 2 \mathrm{R}$ & 2.0 & 4.0 & 2.0 & 2.4 & 54 \\
\hline
\end{tabular}




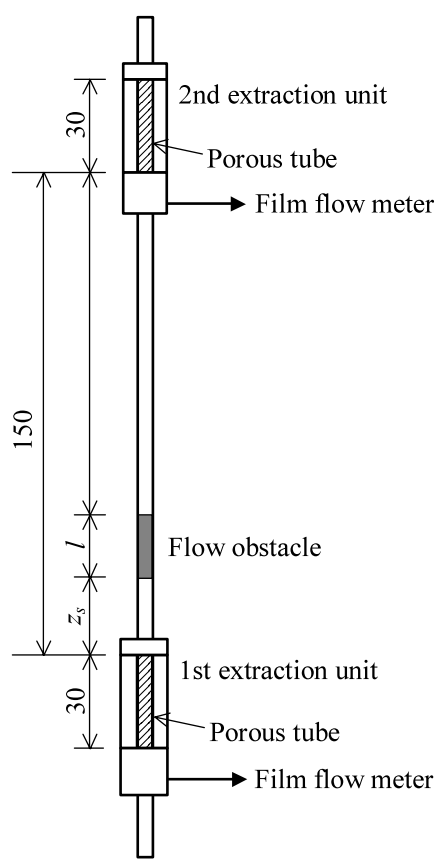

(a) Redeposition section

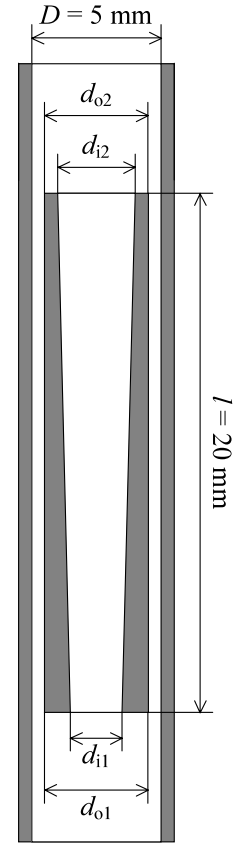

(b) Flow obstacle
Fig. 3 Schematic diagrams of redeposition section and flow obstacle

eas of obstacles were determined to cover the blockage ratio of grid spacers used in fuel assemblies. The crosssections of other four obstacles N1, N1R, N2 and N2R were varied gradually in the axial direction to investigate the mechanism of deposition enhancement found in the previous study ${ }^{(23)}$; the type-N1 and type-N1R obstacles had constant outside diameter as schematically shown in Fig. 3 (b) while the type-N2 and type-N2R obstacles had constant inside diameter. The cross-sectional shapes of both ends of type-N1 and type-N1R obstacles were identical to those of type-X1 and type-X2 obstacles while the cross-sectional shapes of both ends of type-N2 and typeN2R obstacles were almost the same as those of type-S2 and type-X2 obstacles.

The distance between the top of first film extraction unit and the bottom of flow obstacle $z_{\mathrm{s}}$ were 20 or $54 \mathrm{~mm}$. Each flow obstacle had six legs to be fixed in the acrylic test section tube. The legs were $0.5 \mathrm{~mm}$ thick and attached to both ends of flow obstacle. It is expected from the results of our previous experiments that $z_{\mathrm{s}}$ and leg shape had minor influence on the total deposition rate within the redeposition section $^{(23)}$.

\subsection{Method to calculate overall deposition mass transfer coefficient}

The double film extraction technique that was developed previously by Cousins and Hewitt ${ }^{(5)}$ was used to deduce the overall deposition mass transfer coefficient. As schematically shown in Fig. 2, the liquid film was completely extracted at the first extraction unit but a new liquid film was built up between the first and second extrac- tion units due to the redeposition of droplets. If the film Reynolds number $R e_{\mathrm{f}}$ does not exceed the critical film Reynolds number for the onset of entrainment $R e_{\mathrm{fc}}$ significantly, a certain distance is necessary for the droplet entrainment to occur ${ }^{(26)}$. It was hence assumed that the entrainment rate within the redeposition section was negligible if the following criterion was satisfied at the exit of redeposition section:

$$
\frac{R e_{\mathrm{f}}}{R e_{\mathrm{fc}}}<2
$$

where $R e_{\mathrm{fc}}$ was estimated from the empirical correlation by Owen and Hewitt ${ }^{(27)}$. If this criterion was not satisfied, the experimental data were eliminated from further consideration. Since the entrainment rate in the redeposition section might be negligible, the flowrate of new liquid film that was extracted at the second extraction unit gave the measure of deposition rate of droplets. Since the film flowrate was generally smaller at the second extraction unit than at the first, the extracted air flowrate was varied within the reduced range of $1-5 \%$ of total air flowrate for the complete extraction of liquid film. The film flowrate at the second film extraction unit was measured with the same procedure that was used at the first unit.

In order to express the deposition rate $m_{\mathrm{d}}$ with simple equations, it is generally assumed that $m_{\mathrm{d}}$ is proportional to the mass concentration of droplets in the gas core that is denoted by $C$ through a deposition mass transfer coefficient $k_{\mathrm{d}}$ :

$$
m_{\mathrm{d}}=k_{\mathrm{d}} C
$$

The overall deposition mass transfer coefficient $k_{\mathrm{d}}$ was calculated from the data of the present double film extraction experiments as follows. Postulating that the liquid film is thin and the relative velocity between the gas phase and droplets is small, the axial variation of droplet flowrate $G_{\mathrm{d}}$ between the two liquid film extraction units is expressed by

$$
\frac{d G_{\mathrm{d}}}{d z}=-\frac{4}{D} k_{\mathrm{d}} C \approx-\frac{4}{D} k_{\mathrm{d}} \frac{\rho_{\mathrm{g}} G_{\mathrm{d}}}{G_{\mathrm{g}}}
$$

where $z$ is the axial coordinate and $D$ is the tube diameter. Further assuming that $k_{\mathrm{d}}$ is constant within the redeposition section, $k_{\mathrm{d}}$ is calculated from the present experimental data by

$$
k_{\mathrm{d}}=\frac{G_{\mathrm{g}} D}{4 \rho_{\mathrm{g}} z_{\mathrm{d}}} \ln \frac{G_{\mathrm{d} 1}}{G_{\mathrm{d} 2}}
$$

where $z_{\mathrm{d}}$ denotes the distance between the first and second film extraction units (deposition length); $G_{\mathrm{d} 1}$ and $G_{\mathrm{d} 2}$ in Eq. (4) denote the droplet flowrates at the first and second film extraction units, respectively (see Fig. 2).

\section{Results and Discussion}

\subsection{Overall deposition rate}

The ranges of main experimental parameters are listed in Table 2. Govan et al. ${ }^{(6)}$ showed that the dimen- 
Table 2 Main experimental conditions

\begin{tabular}{ccccc}
\hline Type & $\begin{array}{c}P \\
(\mathrm{kPa})\end{array}$ & $\begin{array}{c}J_{1} \\
(\mathrm{~cm} / \mathrm{s})\end{array}$ & $\begin{array}{c}J_{\mathrm{g}} \\
(\mathrm{m} / \mathrm{s})\end{array}$ & $\begin{array}{c}\text { No. of } \\
\text { data }\end{array}$ \\
\hline None & $223-661$ & $4.1-40$ & $36-100$ & 71 \\
$\mathrm{X} 1$ & $230-472$ & $4.3-47$ & $55-85$ & 16 \\
$\mathrm{X} 2$ & $250-578$ & $3.9-37$ & $39-77$ & 35 \\
$\mathrm{~S} 2$ & $226-478$ & $4.5-46$ & $55-85$ & 28 \\
N1 & $273-639$ & $7.2-33$ & $50-69$ & 15 \\
N1R & $340-611$ & $7.2-35$ & $53-71$ & 21 \\
N2 & $238-547$ & $4.3-39$ & $52-79$ & 31 \\
N2R & $266-567$ & $7.6-38$ & $51-78$ & 21 \\
\hline
\end{tabular}

sionless deposition mass transfer coefficient $k_{\mathrm{d}}^{*}$ for various fluids is correlated fairly well with the dimensionless droplet concentration $C^{*}$; the definitions of these dimensionless parameters are:

$$
\begin{aligned}
& k_{\mathrm{d}}^{*}=k_{\mathrm{d}} \sqrt{\frac{\rho_{\mathrm{g}} D}{\sigma}} \\
& C^{*}=\frac{C}{\rho_{\mathrm{g}}}
\end{aligned}
$$

The measured results of $k_{\mathrm{d}}^{*}$ are plotted against $C^{*}$ in Fig. 4 (a) and (b), where the following empirical correlation by Okawa and Kataoka ${ }^{(28)}$ is also depicted for comparison.

$$
\begin{aligned}
& k_{\mathrm{d}}^{*}=\min \left[0.19\left(C^{*}\right)^{-0.2}, 0.105\left(C^{*}\right)^{-0.8}\right] \times F\left(z_{\mathrm{d}}^{*}\right) \\
& F\left(z_{\mathrm{d}}^{*}\right)=0.28+0.72 e^{-0.08 z_{\mathrm{d}}^{*}}
\end{aligned}
$$

where the dimensionless deposition length $z_{\mathrm{d}}^{*}$ is defined by $z_{\mathrm{d}}^{*}=z_{\mathrm{d}} / D$. The figures indicate that the measured data of $k_{\mathrm{d}}^{*}$ agree with Eq. (7) fairly well if no obstacle was placed in the redeposition section while $k_{\mathrm{d}}^{*}$ markedly increased if a flow obstacle was placed. Comparing the results for the three tubular obstacles $\mathrm{X} 1, \mathrm{X} 2$ and $\mathrm{S} 2$, the increasing rate is particularly larger for the type-X2 obstacle. The blockage ratio of X2 was 0.48 and much larger than those of X1 $(0.12)$ and S2 (0.10). It is hence expected that the increase in blockage ratio leads to the augmentation of droplet deposition by a flow obstacle. Both ends of N1 and N1R obstacles were identical to the cross-sections of X1 and $\mathrm{X} 2$. It may hence be probable that the values of $k_{\mathrm{d}}^{*}$ for $\mathrm{N} 1$ and N1R are intermediate between those for X1 and X2. It is however depicted in Fig. 4 (a) that the measured data of $k_{\mathrm{d}}^{*}$ for N1 and N1R are almost overlapped with those for X2. The same conclusion can be applied to the data for N2 and N2R as depicted in Fig. 4 (b). Though the four flow obstacles N1, N1R, N2 and N2R had different geometries as shown in Table 1, their influences on the deposition rate were similar to that of X2. The common feature of these five flow obstacles is the cross-sectional shape at the maximum cross-sectional area. It is considered from the present experimental data that the increas-

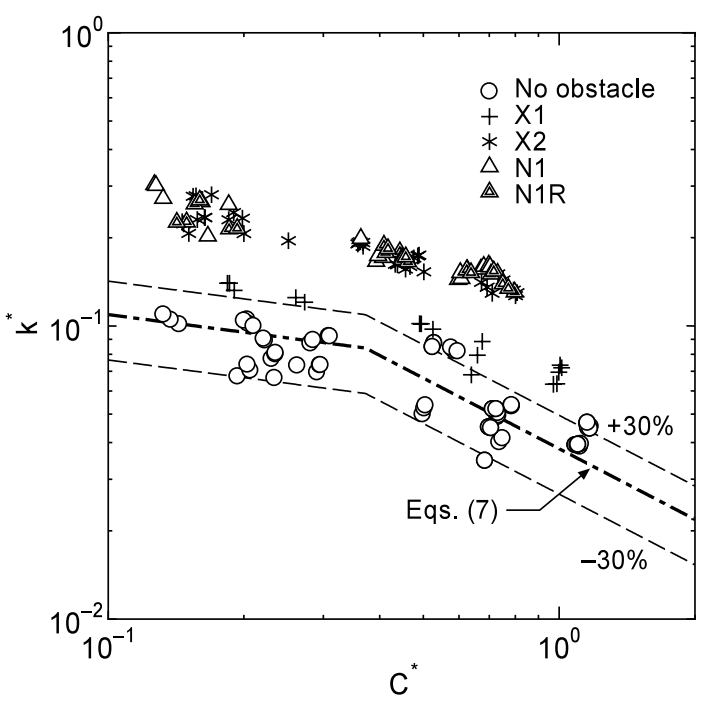

(a) Results for X1, X2, N1, N1R

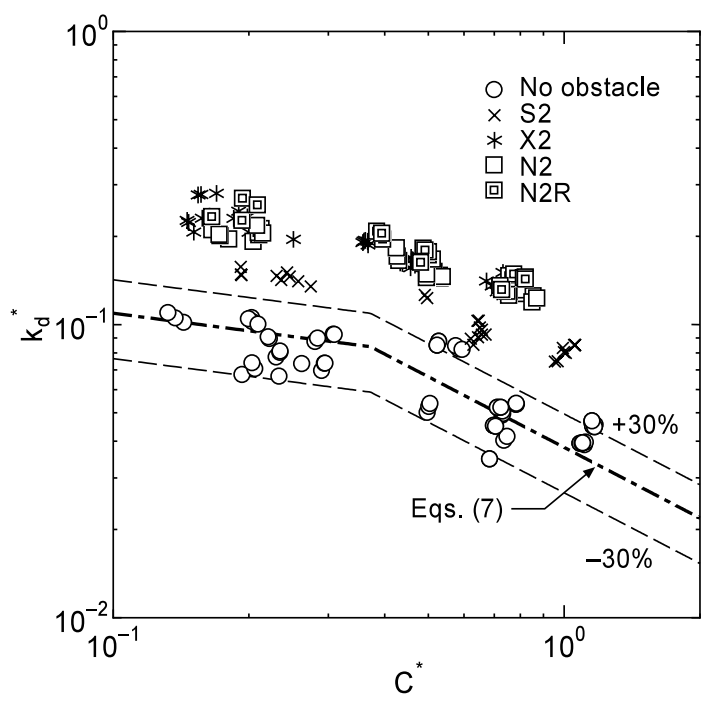

(b) Results for S2, X2, N2, N2R

Fig. 4 Experimental data of overall deposition mass transfer coefficient

ing rate of droplet deposition caused by a flow obstacle depends primarily upon the cross-sectional shape at the maximum cross-sectional area.

\section{2 Obstacle-induced deposition rate}

To estimate the deposition rate induced by the present tubular obstacles, the redeposition section is divided into the upstream, obstacle and downstream sections ${ }^{(23)}$. The relation between the droplet flowrates at the inlet and the exit of deposition section $G_{\mathrm{d} 1}$ and $G_{\mathrm{d} 2}$ is expressed by

$$
G_{\mathrm{d} 2}=G_{\mathrm{d} 1} \exp \left[-\frac{4 \rho_{\mathrm{g}}}{G_{\mathrm{g}} D}\left(k_{\mathrm{du}} z_{\mathrm{du}}+k_{\mathrm{ds}} z_{\mathrm{ds}}+k_{\mathrm{dd}} z_{\mathrm{dd}}\right)\right]
$$

where the subscripts u, s and d denote the upstream, obstacle and downstream sections, respectively. Assuming that $z_{\mathrm{ds}}$ is sufficiently shorter than $z_{\mathrm{d}}$ and approximated by $D$, Eq. (9) is transformed to

$$
G_{\mathrm{d} 2}=G_{\mathrm{d} 1} \exp \left[-\frac{4 \rho_{\mathrm{g}}}{G_{\mathrm{g}} D}\left(k_{\mathrm{d} 0} z_{\mathrm{d}}+k_{\mathrm{ds}} D\right)\right]
$$




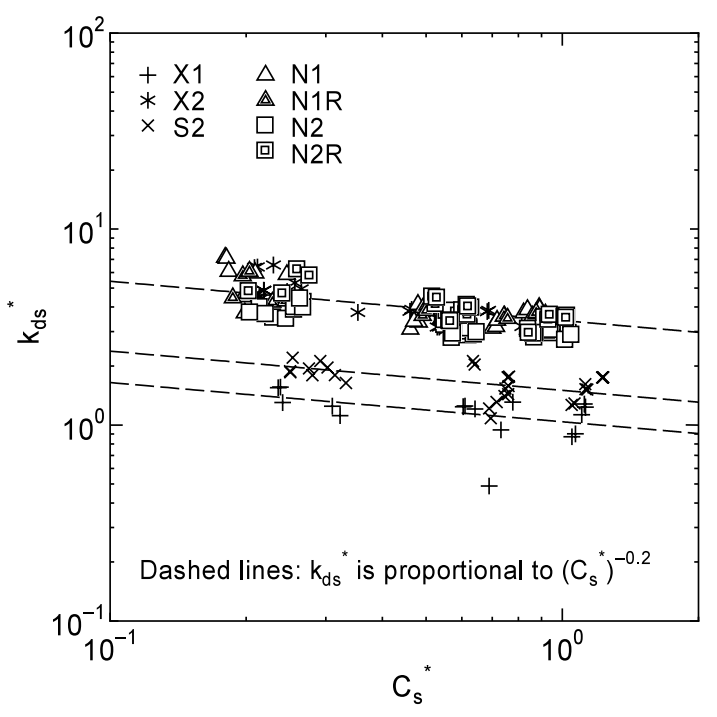

Fig. 5 Dependence of obstacle-induced deposition mass transfer coefficient on droplet concentration

where $k_{\mathrm{d} 0}$ is the averaged deposition mass transfer coefficient within the upstream and downstream sections defined by

$$
k_{\mathrm{d} 0}=\frac{k_{\mathrm{du}} z_{\mathrm{du}}+k_{\mathrm{dd}} z_{\mathrm{dd}}}{z_{\mathrm{d}}}
$$

Further assuming that Eq. (7) is applicable to estimate $k_{\mathrm{d} 0}$, $k_{\mathrm{ds}}$ is calculated from Eq. (10). The dependences of $k_{\mathrm{ds}}^{*}$ on $C_{\mathrm{s}}^{*}$ are depicted in Fig. 5. Here, the droplet concentration at flow obstacle $C_{\mathrm{s}}$ is estimated by

$$
C_{\mathrm{s}}=\frac{\rho_{\mathrm{g}} G_{\mathrm{ds}}}{G_{\mathrm{g}}}=\frac{\rho_{\mathrm{g}} G_{\mathrm{d} 1}}{G_{\mathrm{g}}} \exp \left[-\frac{4 \rho_{\mathrm{g}}}{G_{\mathrm{g}} D} k_{\mathrm{d} 0} z_{\mathrm{s}}\right]
$$

There appears weak dependence of $k_{\mathrm{ds}}^{*}$ on $C_{\mathrm{s}}^{*}$ and the values of $k_{\mathrm{ds}}^{*}$ deduced from the present method may be correlated by

$$
k_{\mathrm{ds}}^{*}=K\left(C_{\mathrm{s}}^{*}\right)^{-0.2}
$$

where $K$ is the proportionality factor. In order to reveal the influence of obstacle geometry on $k_{\mathrm{ds}}^{*}$, the dependence of $K$ on the blockage ratio $\beta_{\mathrm{b}}$ and the diameter ratio $\beta_{\mathrm{d}}$ was investigated. The definitions of these geometric parameters are

$$
\begin{aligned}
& \beta_{\mathrm{b}}=\frac{d_{\mathrm{o}}^{2}-d_{\mathrm{i}}^{2}}{D^{2}} \\
& \beta_{\mathrm{d}}=\frac{d_{\mathrm{i}}+d_{\mathrm{o}}}{2 D}
\end{aligned}
$$

where the inside diameter $d_{\mathrm{i}}$ and the outside diameter $d_{\mathrm{o}}$ are determined from the cross-sectional shape of flow obstacles at the maximum cross-sectional area. The results obtained after several trials are depicted in Fig. 6. It appeared that $K$ increases with $\beta_{\mathrm{b}}$ while decreases with $\beta_{\mathrm{d}}$ and is correlated by

$$
K=4.3 \beta_{\mathrm{b}}^{0.9} \beta_{\mathrm{d}}^{-1.1}
$$

It is confirmed that axial variation of cross-sectional shape is different in the flow obstacles N1, N1R, N2 and N2R

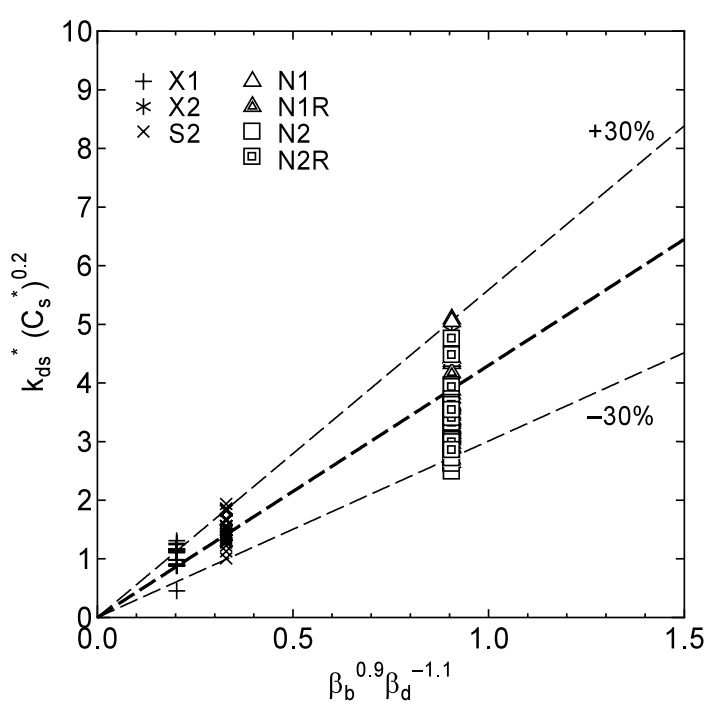

Fig. 6 Dependence of obstacle-induced deposition mass transfer coefficient on geometric parameters

but the deposition rate induced by these four obstacles are correlated fairly well solely from the cross-sectional shape at the maximum cross-sectional area.

\subsection{Prediction of exit film flowrate}

In order to confirm the applicability of empirical correlation Eq. (16) to the present experimental conditions, the film flowrate measured at the second film extraction unit $G_{\mathrm{f} 2}$ was calculated using Eq. (10). The results are depicted in Fig. 7 (a) and (b). The obstacle-induced deposition is neglected in Fig. 7 (a) while accounted by Eqs. (13) and (16) in Fig. 7 (b). When the obstacle-induced deposition is not taken into consideration, $G_{\mathrm{f} 2}$ is significantly underestimated as shown in Fig. 7 (a). On the other hand, fairly good agreement with the present experimental data is achieved if the obstacle-induced deposition is evaluated with the present empirical correlation as shown in Fig. 7 (b).

\section{Conclusions}

Experiments were conducted to reveal the effect of obstacle shape on the deposition rate of droplets in annular two-phase flow. In the present experiments, the test section was a vertical round tube of $5 \mathrm{~mm}$ in inside diameter, air and water were used as test fluids, and double film extraction technique was adopted for the measurement. Seven tubular pieces of different specifications were used as flow obstacles.

In all the experimental conditions tested, the deposition rate was markedly increased by a flow obstacle. Though the obstacles were $11 \%$ of the whole redeposition section in axial length, the overall deposition mass transfer coefficient became approximately $1.3-3$ times larger if a tubular obstacle is placed concentrically in the flow channel. The increasing rate was depended primarily upon the obstacle shape. The obstacle-induced deposition 


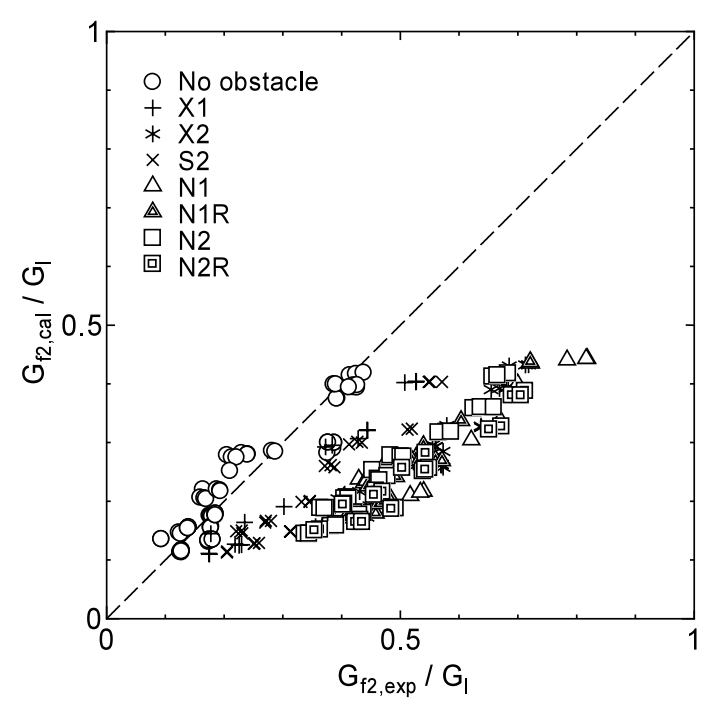

(a) Obstacle-induced droplet deposition is not accounted

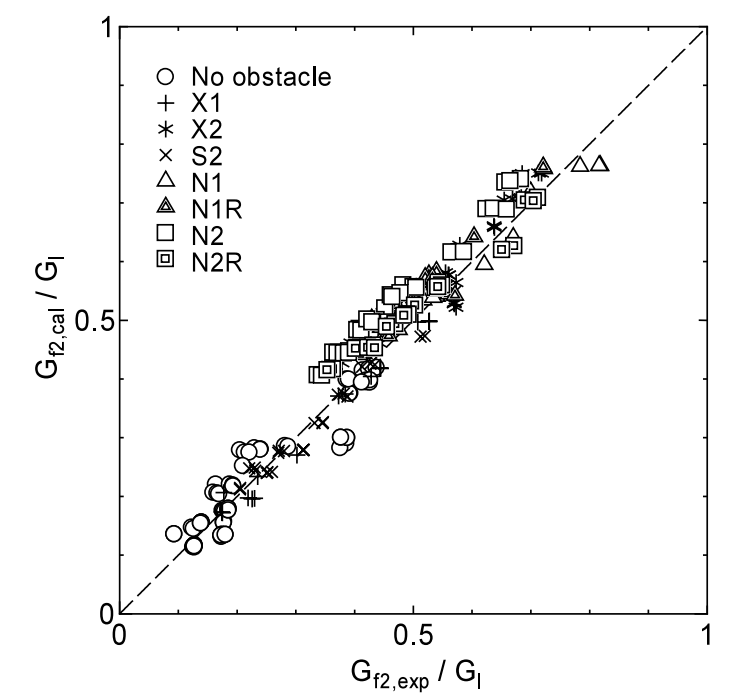

(b) Obstacle-induced droplet deposition is accounted with Eqs. (13) and (16)

Fig. 7 Comparisons of calculated fractional film flowrate at the exit of redeposition section with experimental data

mass transfer coefficient was increased with the increase in blockage ratio while decreased with the increase in obstacle diameter. An empirical correlation for the obstacleinduced deposition mass transfer coefficient was derived from the present experimental results. It was confirmed that the film flowrate at the exit of redeposition section was significantly underestimated if the obstacle effect was neglected but fairly good agreement was achieved if the obstacle effect was accounted with the proposed correlation.

The influence of the axial variation of cross-sectional shape of flow obstacle on the deposition rate was also investigated. It was found that the deposition augmentation was dependent primarily upon the cross-sectional shape of a flow obstacle at the maximum cross-sectional area; un- expectedly, other geometric parameters had minor influence on the deposition rate within the four obstacles tested in the present study.

If the effect of flow obstacle was not taken into consideration, the film flowrate downstream the obstacle was underestimated significantly. This implies that the critical heat flux in nuclear reactor core caused by film dryout may be underestimated if the effect of grid spacer on the deposition rate is not accounted. The proposed empirical correlation for the obstacle-induced droplet deposition was satisfactory within the present experimental ranges but its validity to high-pressure steam-water annular flow was not tested because of the lack of experimental data. Further experiments are considered necessary to develop a reliable model for the droplet mass transfer rate in a flow channel containing obstacles.

\section{Acknowledgement}

This work was funded by the Institute of Applied Energy (IAE), and Ministry of Economy, Trade and Industry (METI).

\section{References}

( 1 ) Hewitt, G.F., Kearsey, H.A., Lacey, P.M.C. and Pulling, D.J., Burnout and Nucleation in Climbing Film Flow, International Journal of Heat and Mass Transfer, Vol.8 (1965), pp.793-814.

(2) Naitoh, M., Ikeda, T., Nishida, K., Okawa, T. and Kataoka, I., Critical Power Analysis with Mechanistic Models for Nuclear Fuel Bundles (I): Models and Verifications for Boiling Water Reactor Applications, Journal of Nuclear Science and Technology, Vol.39, No.1 (2002), pp.40-52.

( 3 ) Okawa, T., Kotani, A., Kataoka, I. and Naito, M., Prediction of Critical Heat Flux in Annular Flow Using a Film Flow Model, Journal of Nuclear Science and Technology, Vol.40, No.6 (2003), pp.388-396.

( 4 ) Okawa, T., Kotani, A., Kataoka, I. and Naitoh, M., Prediction of the Critical Heat Flux in Annular Regime in Various Vertical Channels, Nuclear Engineering and Design, Vol.229 (2004), pp.223-236.

( 5 ) Cousins, L.B. and Hewitt, G.F., Liquid Phase Mass Transfer in Annular Two-Phase Flow: Droplet Deposition and Liquid Entrainment, AERE-R5657, (1968).

( 6 ) Govan, A.H., Hewitt, G.F., Owen, D.G. and Bott, T.R., An Improved CHF Modelling Code, Proceedings of the 2nd UK National Heat Transfer Conference, (1988), pp.33-48.

( 7 ) Schadel, S.A., Leman, G.W., Binder, J.L. and Hanratty, T.J., Rates of Atomization and Deposition in Vertical Annular Flow, International Journal of Multiphase Flow, Vol.16 (1990), pp.363-374.

( 8 ) Lopez de Bertodano, M.A., Assad, A. and Beus, S.G., Experiments for Entrainment Rate of Droplets in the Annular Regime, International Journal of Multiphase Flow, Vol.27 (2001), pp.685-699.

(9) Okawa, T., Kotani, A. and Kataoka, I., Experiments for Equilibrium Entrainment Fraction in a Small Vertical 
Tube, Proceedings of 5th International Conference on Multiphase Flow, (2004), Paper No.224.

(10) McCoy, D.D. and Hanratty, T.J., Rate of Deposition of Droplets in Annular Two-Phase Flow, International Journal of Multiphase Flow, Vol.3 (1977), pp.319-331.

(11) Ishii, M. and Mishima, K., Droplet Entrainment Correlation in Annular Two-Phase Flow, International Journal of Heat and Mass Transfer, Vol.32 (1988), pp.18351846.

(12) Sugawara, S., Droplet Deposition and Entrainment Modeling Based on the Three-Fluid Model, Nuclear Engineering and Design, Vol.122 (1990), pp.67-84.

(13) Okawa, T., Kitahara, T., Yoshida, K., Matsumoto, T. and Kataoka, I., New Entrainment Rate Correlation in Annular Two-Phase Flow Applicable to Wide Range of Flow Condition, International Journal of Heat and Mass Transfer, Vol.45 (2002), pp.87-98.

(14) Yokobori, S., Ohta, M., Terasaka, H. and Morooka, S., A Phenomenological Study on the Dryout Mechanism in a Fuel Rod, Proceedings of 4th International Topical Meeting on Nuclear Reactor Thermal-Hydraulics, (1989), pp.1054-1061.

(15) Chung, J.B., Baek, W.-P. and Chang, S.H., Effects of the Spacer and Mixing Vanes on Critical Heat Flux for Low-Pressure Water at Low-Velocities, International Communications in Heat and Mass Transfer, Vol.23, No.6 (1996), pp.757-765.

(16) Pioro, L., Groeneveld, D.C., Doerffer, S.S., Guo, Y., Cheng, S.C. and Vasic, A., Effects of Flow Obstacles on the Critical Heat Flux in a Vertical Tube Cooled with Upward Flow of R-134a, International Journal of Heat and Mass Transfer, Vol.45 (2002), pp.4417-4433.

(17) Mori, S. and Fukano, T., Influence of a Flow Obstacle on the Occurrence of Burnout in Boiling Two-Phase Upward Flow within a Vertical Annular Channel, Nuclear Engineering and Design, Vol.225 (2003), pp.4963.

(18) Lee, M., A Critical Heat Flux Approach for Square Rod Bundles Using the 1995 Groeneveld CHF Table and Bundle Data of Heat TransferResearch Facility, Nu- clear Engineering and Design, Vol.197 (2000), pp.357374.

(19) Yamamoto, Y. and Morooka, S., Study on Critical Power Prediction of BWR Fuel Assembly, Proceedings of 3rd International Conference on Multiphase Flow, (1998), Paper No.653.

(20) Matida, E.A., Nishino, K. and Torii, K., Statistical Simulation of Particle Deposition on the Wall from Turbulent Dispersed Pipe Flow, International Journal of Fluid Flow, Vol.21 (2000), pp.389-402.

(21) Akiba, M., Morooka, S., Yamamoto, Y. and Hoshide, A., Effects of the Spacer on Liquid Film Flow Rate in Fuel Rod Bundle, Japanese Journal of Multiphase Flow, (in Japanese), Vol.12, No.2 (1998), pp.144-150.

(22) Yano, T., Aritomi, M., Kikura, H. and Obata, H., Mechanistic Modeling for Ring-Type Boiling Water Reactor Fuel Spacer Design (3): Run-Off Effect and Model Formulation, Nuclear Engineering and Design, Vol.210 (2001), pp.21-36.

(23) Okawa, T., Kotani, A., Shimada, N. and Kataoka, I., Effects of a Flow Obstacle on the Deposition Rate of Droplets in Annular Two-Phase Flow, Journal of Nuclear Science and Technology, Vol.41, No.9 (2004), pp.871-879.

(24) Hewitt, G.F., Liquid-Phase Mass Transfer Rate in Annular Flow, Edited by Hetsroni, G., Handbook of Multiphase Systems, (1982), Sec.10.2.2.4, McGraw-Hill, New York.

(25) Wallis, G.B., One-Dimensional Two-Phase Flow, (1969), Chap. 11, McGraw-Hill, New York.

(26) Cousins, L.B., Denton, W.H. and Hewitt, G.F., Liquid Mass Transfer in Annular Two-Phase Flow, Proceedings of Symposium on Two-Phase Flow, Exeter, (1965), Paper No.C4.

(27) Owen, D.G. and Hewitt, G.F., A Proposed Entrainment Correlation, AERE-R12279, (1986).

(28) Okawa, T. and Kataoka, I., Correlations for the Mass Transfer Rate of Droplets in Vertical Upward Annular Flow, International Journal of Heat and Mass Transfer, Vol.48 (2005), pp.4766-4778. 